\title{
Contra o reducionismo na redução da maioridade penal
}

Against reductionism in reducing the legal criminal age

Contra el reduccionismo en la reducción de la mayoría de edad penal

Andréa Máris Campos Guerra*

\section{A cultura e sua discursividade}

V ivemos um tempo historicamente marcado pelos moldes do funcionamento neoliberal e capitalista. Nele, a alteridade se reduz e se desconfigura como horizonte ético, a diferença incomoda, a improdutividade implica exclusão e ameaça (Drawin, 2008). Por outro lado, o cientificismo (Hacking, 2005) nomeia o mal-estar, diagnostica individualmente o sofrimento e cria, com isso, novos nomes com os quais subjetividades são moldadas (Dunker, 2015), excluindo-se as experiências singulares com o corpo e com a palavra, bem como retirandose, dessa forma, a dimensão política incluída nessas classificações. Além disso, a fluidez dos laços e a rigidez dos espaços configuram zonas territoriais e simbólicas nas cidades, cuja ocupação é marcada pelo medo e pela insegurança, produzindo como efeito a restrição da circulação, a segregação e a proteção discriminatória (Bauman, 2009; Telles, 2010).

Discursividades se configuram nesse quadro, desenhando a figura de um inimigo comum que unifica a diversidade e pacifica as massas, ao concentrar, de maneira maniqueísta, a figura do mal. Não é diferente no contexto brasileiro. Apesar dos estudos antropológicos que extraem a figura da ralé e do batalhador brasileiros, em meio a uma ideia genérica de classe social (Souza, 2012), ainda permanecemos na generalização. Associamos a pobreza à criminalidade, os aglomerados urbanos à violência, o menor ao crime. Insistimos em desconhecer as condições desiguais da distribuição das riquezas que produz o fosso urbano que sectariza experiências de vida, também o destino e a finalidade das estatísticas de mortalidade juvenil, as condições pelas quais a criminalidade se estabelece no País e a maneira como sacrificamos populações inteiras, sem nos darmos conta de que o fazemos.

Nesse quadro, surge, no contexto político brasileiro, a proposta de redução da maioridade penal, tramitando no Congresso, por meio da Proposta de Emenda

\footnotetext{
Doutora em Teoria Psicanalítica pela Universidade Federal do Rio de Janeiro (UFRJ) com Études Approfondes em Rennes II (França); mestra em Psicologia Social pela Universidade Federal de Minas Gerais (UFMG); professora adjunta do Departamento e da Pós-Graduação em Psicologia do Departamento de Psicologia da Fafich/UFMG; psicóloga; bacharela em Direito; psicanalista; membro do GT "Dispositivos clínicos em saúde mental” da ANPEPP. Endereço: Rua Mares de Montanhas, 1325 - Vale dos Cristais, Nova Lima-MG, Brasil. CEP: 34000-000. E-mail: andreamcguerra@gmail.com.
} 
Constitucional (PEC) n. ${ }^{\circ}$ 171/1993 (Domingos, 1993), que propóe alteração da redação do artigo 228 da Constituição Federal, para reduzir de 18 para 16 anos a maioridade penal. Agora alterada para ser aplicada apenas aos casos de infrações equivalentes a crimes hediondos.

\section{O cerne da questão da maioridade penal}

A variação legislativa quanto à maioridade que se discute hoje no Brasil diz respeito à idade penal, cuja determinação legal redefinirá um dos elementos da configuração do crime. Para que uma ação, no âmbito jurídico, seja considerada criminosa, ela exige três elementos: a tipicidade (o fato praticado tem de ser tipificado como o que a lei prevê como conduta ilícita), a antijuricidade (o fato praticado precisa ser consciente ou volitivamente praticado com a intenção ou previsão de causar dano ou lesão) e a culpabilidade (capacidade de o autor do fato reconhecer o que é lícito e agir ou não em conformidade com esse procedimento) (Jesus, 2013). Ao menor de 18 anos, ao ser tomado como sujeito especial em condição de desenvolvimento, não é atribuível a culpabilidade por conta desse recorte etário. Não se configura, assim, o crime, mas antes a infração. Cabe medida socioeducativa no lugar da pena, centro socioeducativo no lugar da cadeia.

Por que é importante entender tudo isso? É exatamente a discussão acerca da capacidade de resposta do jovem quanto aos atos que comete e suas consequências legais que definirão uma política mais ampla de inclusão de sua presença na cena pública. Tomar os 16 ou 18 anos como marco legal, com maior ou menor flexibilidade (como algumas propostas legislativas se apresentam na Assembleia) implica não apenas avaliar a capacidade de resposta de um sujeito em desenvolvimento como também indicar seu destino, em escala social mais ampla. $\mathrm{O}$ que isso quer dizer? Quando lemos em um jornal "menor assalta adolescente", muitas vezes, não temos a dimensão do que está em jogo no sectarismo com que operamos. Daí a necessária ampliação do espectro analítico em jogo nessa discussão.

A questão da redução da maioridade penal implica, pois, em tomarmos diferentes aspectos em questão:

a) a narrativa social que temos da adolescência e da juventude, desde o Código de Menores até o Estatuto da Criança e do Adolescente (ECA) e o Estatuto da Juventude;

b) a diferença econômica da criança e do adolescente, e sua interpretação como potência ou como obstáculo ao desenvolvimento do País; 
c) a especificidade da experiência da adolescência como tempo de travessia da infância para a vida adulta para cada sujeito;

d) o estatuto da resposta do adolescente diante de seu ato;

e) as consequências políticas e jurídicas dessa atribuição de capacidade de resposta ou de responsabilidade ao adolescente;

f) a responsabilidade social com que nos engajamos ou nos demitimos dessa problemática;

g) a concepção de culpa e castigo imbuída na noção de resposta que alocamos somente ao jovem, como se dela não fizéssemos parte e não a construíssemos com ele;

h) o destino institucional que outorgamos a esse segmento jovem brasileiro;

i) a aposta, nem sempre evidente e nem sempre realizada, que fazemos quanto às suas possibilidades de construção de outras rotas de vida, diferentes daquelas referidas ao crime;

j) o risco de morte que podemos ou não destacar com a redução da maioridade penal.

Como se vê, trata-se de discussão da mais ampla envergadura que nos engaja a todos com nossos conceitos e preconceitos, consolidando uma concepção de País, de cidadania, de juventude, de participação social, de subjetividade e de responsabilidade, que não pode ser apenas pensada em relação ao jovem brasileiro. Quando decidimos, ou não, pela redução da maioridade, estamos às voltas com a construção de uma política societária que interfere no destino de nosso País. Por que abrir mão de uma conquista social?

\section{O modelo socioeducativo e seu desconhecimento em massa}

Como é de conhecimento notório, o ECA (Lei Federal no 8.069/1990) foi, a seu tempo, uma conquista de movimentos sociais, tendo sido tomado como legislação à frente de seu tempo. Ele inaugurou, na década de 1990, uma nova concepção jurídica (com forte impacto social) de criança e adolescente, de sujeito de direitos e deveres, de responsabilidade compartilhada, de rede de proteção e socioeducação. À recorrência da imagem midiática dos menores em rebelião na "FEBEM" o ECA interpôs a necessária e urgente revisão de seu modelo discursivo e operativo, calcado na segregação, no castigo e na violência. 
É rápida e fácil a repetição de frases como "não dá nada para menor no Brasil", "melhor matarem-se entre si a virem em cima de nós", "favela (ou prisão) é fábrica de criminoso", "com uma mão mais pesada, eles vão aprender", como se a solução para a redução da criminalidade e da violência estivesse na intensidade do castigo aplicada individualmente a cada condenado, como se não houvesse questôes muito mais complexas ... Difícil é nos perguntar como esses jovens negros se tornaram os quase $70 \%$ que morrem anualmente no País ... Ou por que, enquanto em Portugal apenas um cidadão foi morto em abordagem policial de rua no ano de 2006, no Estado do Rio de Janeiro, 1.376 pessoas foram mortas na mesma situação, sob alegação de resistência (ISP-RJ/NECVU-UFRJ apud Cruz, 2015) ... Difícil é contabilizar que jovens, negros, pobres e do sexo masculino morrem 3,7\% mais por homicídio que o restante da população no Brasil (Cano $\&$ Santos, 2007); e não à toa esse quadro se inicia aos 12 anos de idade, idade com que o ECA demarca o fim da infância e o início da adolescência, podendo ser aplicada medida socioeducativa, onde antes cabia apenas a socioprotetiva (Waiselfisz, 2012). Difícil acreditar que nossos dados de mortalidade juvenil ultrapassam os de países em guerra (Anastácio, 2015) A decisão pela redução da maioridade implica abrirmos a condição para que jovens, cada vez mais novos, enfileirem esses dados. Implica em acirrarmos a violação de direitos que, apesar de tão novos, já os aflige e violarmos, agora constitucionalmente, um direito já adquirido.

Como, então, o ECA trata o adolescente, considerado aquele entre 12 e 18 anos, quando ele comete ato equivalente a crime? Não é com a impunidade que ele vai responder (como a desinformação de muitos afirma), mas com a remissão da pena e consequente aplicação das medidas socioeducativas. Isso significa que, não tendo maioridade penal, o ato infracional equivalente a crime previsto no Código Penal vai ser respondido pelo adolescente, mas não do mesmo modo com que lhe responde o adulto. Espera-se, entre os objetivos das medidas, segundo a Lei do SINASE (Lei Federal n. ${ }^{\circ} 12.594 / 2012$ ): responsabilização, desaprovação da conduta e integração social do adolescente. Para esse fim, foi criada uma rede de instituiçóes para atuar com o adolescente, entendendo que, como pessoa em desenvolvimento, sem ter feito necessariamente, e ainda, a decisão pela vida criminosa, ele pode construir uma solução de vida diferente. Essa decisão interfere no conjunto da população brasileira. E, se não encontra apoio, respaldo legal e institucional, perde-se no inferno da boa intenção.

São seis as medidas socioeducativas, aplicadas em substituição à pena: advertência, obrigação de reparar o dano, prestação de serviço à comunidade, liberdade assistida, inserção em regime de semiliberdade, internação em estabelecimento educacional, que pode durar de seis meses a três anos. São 
aplicadas conforme a capacidade de o jovem cumpri-las, as circunstâncias e a gravidade do fato, considerando-se também a reincidência (Lei Federal n. ${ }^{\circ}$ 8.069/1990). À diferença do modelo prisional para adultos, regido pelo Direito Penal, a execução das medidas implica numa série de ações institucionais correlatas, como a exigência da frequência à escola, a oferta de formação profissional complementar e a inserção sociofamiliar. Mesmo internado, isto é, privado de liberdade, o adolescente pode efetuar atividades externas, visando a seu retorno ao "mundão", como costumam dizer, além de estudar, participar de oficinas e receber acompanhamento dentro dos centros a eles destinados.

Parece um idílio ou um conto de fadas? Mas definitivamente não o é. Num período de intensas atuações, desejos e indecisões, submeter o corpo rebelde a uma outra oferta sancionada por lei implica um corte na vida, uma imposição da norma, uma espécie de enjaulamento. Se, porém, distintamente do binômio culpa-castigo, entendemos as medidas no eixo responsabilidade-reorientação, potencializamos a autodeterminação e a resiliência do jovem. Do contrário, elevamos o pior momento da vida de um adolescente (o momento do ato infrator) à condição de sua identidade dali em diante (Soares, 2011). Como sistema, traçamos um roteiro de vida às expensas do próprio sujeito e de sua capacidade de resposta.

Como se vê, o "não dá nada pra mim", que se tornou frase recorrente na boca de jovens e da população adulta ao se referir a estes, não é verdadeira. A privação de até três anos de liberdade no período da adolescência não é sem consequências para ninguém que a experimenta. Da advertência à internação, do castigo (correlato simbólico de um ideal societário), espera-se produzir um ponto de abertura, um novo projeto de vida para o adolescente, o que não é esperado, da mesma maneira, do sistema prisional. Essa é uma diferença central entre os dois sistemas. Acredita-se numa relação proporcional, mesmo sem dados que a confirmem, na qual mais punição corresponde a menos criminalidade. Entretanto, enquanto o sistema prisional mostra a falência dessa relação por meio da superlotação, o sistema socioeducativo aposta na mudança de vida do jovem. Por isso, suas estruturas físicas, legais, simbólicas e sociais, bem como as condições de sua execução, são diferenciadas. Por que essa diferença?

\section{Os jovens e suas travessias}

Um dos pontos que deram origem a essa diferença é o fato simples de que um adolescente ainda não é um adulto, e já não é mais uma criança. Esse intervalo, hoje estabelecido por lei, é da mais alta importância, assim como suas variações internas. Pode-se escolher votar, no Brasil, aos 16 anos, mas aos 18 o voto é 
obrigatório. Pode um jovem se emancipar antes dos 18 anos para se casar, mas, somente aos 18, essa capacidade civil é prevista. Não se tira carteira de motorista antes dos 18 anos de idade no País. Dos 16 aos 18 anos, há trabalho protegido visando à formação do futuro profissional, mas assinatura contratual de trabalho apenas depois dessa idade.

A ficção jurídica aqui visa a resguardar um intervalo que, histórica e culturalmente, sempre variou muito (Le Breton, 2013), tendo mesmo sequer existido durante períodos inteiros (Ariès, 1981). A adolescência é uma construção cultural, cujo marco filosófico se deu com a obra Emílio, ou da Educação, de Rousseau (2004), encontrando ecos na literatura especializada que, posteriormente, elevou a adolescência a uma espécie de crise estrutural. Adolescência e crise, adolescência e coragem, adolescência e revolução, adolescência e violência, adolescência e inovação têm sido variações semânticas corolárias à consolidação da ideia de um período ou fase de vida correspondente a essa faixa de idade. Ela sempre existe? Será que um adolescente de 13 anos, que assume financeiramente sua mãe e seus irmãos com o que aufere na atuação infratora, vive esse intervalo? Encontra meios e tempo para elaborar sua entrada no mundo dos adultos?

A que responde essa construção da adolescência como um intervalo, uma travessia? Para alguns, ela atende a determinações econômicas que exigem o adiamento da entrada de indivíduos no mercado de trabalho para garantir certo equilíbrio na distribuição da força produtiva. É preciso adiar essa entrada para regular o mercado de mão de obra. Para outros, a adolescência é um fato biológico, hormonal, de transformações físicas que se denomina puberdade e será acompanhado pelo saber médico do hebiatra (especialista em adolescência). Para outros, é uma fase de desenvolvimento psíquico no qual serão amadurecidas funções essenciais ao desempenho adulto, como a capacidade sexual e laborativa e o discernimento, sendo necessário um período de moratória social para que seja autorizada sua entrada simbólica no mundo adulto. Na contramão dessa leitura, a juventude toma as rédeas da própria história, sua e de seu mundo, e vem sendo vivamente tomada como atora social central nas tomadas de decisão atinentes à vida pública, como ficou evidente nos movimentos reivindicatórios que tomaram as cidades em 2013.

Como se nota, na ausência de uma medida comum, criamos imagens e teorias que referenciam os jovens, dotando-os de significação comum como categoria. Com isso, perdemos a experiência singular, e também a coletiva, de cada um deles. E mais, como se vê, a definição legal não corresponde nem bem a uma, nem exatamente a outra dessas definiçôes. Nesse sentido, ela deve ser decidida também como construção histórica e como tomada política de decisão quanto 
ao que se espera do jovem na esfera da vida pública, o que o engaja diretamente na esfera da vida privada. Ouvir de uma criança, aos 9 anos, que ela decidiu tocar a própria vida, saindo de casa e indo morar nas ruas, quando constatou que não podia contar com mais ninguém, é diferente de uma criança que, aos 7 anos, faz as malas e encena uma fuga de casa para receber a certeza do amor de seus pais. Vivemos, no Brasil, condições de família, moradia, emprego e circulação muito distantes umas das outras. Posto isso, a redução ou não da maioridade penal vai incidir muito mais diretamente sobre a primeira dessas crianças que sobre a segunda. Por isso é preciso pôr os pingos nos is.

Estamos falando de uma parcela muito específica de adolescentes quando falamos de redução da maioridade penal. E ela é correlata à forma como interpretaremos as adolescências em suas distinções internas. Mesmo com a superação da diferença, no texto legal do Código de Menores (1937), entre abandonado e delinquente em referência ao menor (diferença superada pelo ECA ao consolidar a perspectiva de proteção integral à criança e ao adolescente), discursiva e culturalmente, ainda não rompemos essa forma (pre)conceituosa de pensar o jovem do "asfalto" e o jovem do "morro", a criança "futuro da nação" e a criança "vergonha nacional".

\section{O reducionismo na redução da maioridade penal}

Dessa forma, pensar a redução (ou não) da maioridade penal implica uma perspectiva ontológica, ética e política, que visa esteticamente a projetar o lugar do jovem brasileiro na cena nacional. Estamos escrevendo a história futura do Brasil quanto ao destino de nossos jovens, junto e ao lado deles. Afinal, quem entrou aos brados na Assembleia em uma das votaçóes da PEC 171? Eles, nossa juventude, que, sempre falada pelos adultos, arromba a porta, entra e se afirma na posição imperturbável e, por isso, tão perturbadora, de dizer que pode responder, na boa medida, e acompanhados por seus atos. Não será, então, a nossa capacidade de resposta, a nossa responsabilidade de adultos moradores da polis, que deveria estar em questão? Como reduzir, ou retirar dos adolescentes, esse direito já adquirido? Como não apostar ao lado deles? Dizer não à redução da maioridade penal é dizer sim à nossa juventude em toda a sua complexidade. É estar ao lado, ali mesmo onde um lugar vazio poderia engendrar o pior . . . $\mathrm{O}$ não ao reducionismo da questão alarga, nesse ponto, o horizonte de nossos adolescentes ... E também, ao que tudo indica, também o nosso. 


\section{Referências}

Anastácio, E. (2015). Bauman e Rancière: notas para um debate preciso. In A. M. C. Guerra, C. F. Cunha, R. S. Silva (Orgs.), Violência, território, família e adolescência: contribuiçôes para a política de assistência social. (pp. 87-96). Belo Horizonte: Scriptum.

Ariès, P. (1981). História social da criança e da família. (2a ed.). Rio de Janeiro: LTC.

Bauman, Z. (2009). Confiança e medo na cidade. Rio de Janeiro: Zahar.

Cano, I. \& Santos, N. (2007). Violência letal, renda e desigualdade no Brasil. Rio de Janeiro: Sete Letras.

Cruz, A. D. G. (2015). O fundamento da razão sacrificial e os paradoxos do Nome do Pai. (Tese de Doutorado). Pontifícia Universidade Católica de Minas Gerais, Programa de Pós-Graduação em Psicologia, Belo Horizonte.

Domingos, B. (1993, 19 Agosto). PEC 171/1993. Proposta de Emenda à Constituição. Brasília: Câmara. Recuperado a partir de http://www.camara. gov.br/proposicoesWeb/fichadetramitacao?idProposicao=14493.

Drawin, C.s R. (2008). A razão ensombrecida: conjecturas filosóficas acerca do progresso do saber. In C. A. L. Brandão (Org.), A república dos saberes: arte, ciência, universidade e outras fronteiras. Belo Horizonte: Editora UFMG.

Dunker, C. I. L. (2015). Mal-estar, sofrimento e sintoma: uma psicopatologia do Brasil entre muros. São Paulo: Boitempo.

Hacking, I. (2005). Façonner les gens II. In Philosophie et histoire des concepts scientifiques. (Resumo de curso). Paris: Collège de France. Recuperado a partir de http://www.college-de-france.fr/media/professeurs-honoraires/ UPL46353_UPL35833_hackingres0405.pdf.

Jesus, D. (2013). Direito penal: parte geral. São Paulo: Saraiva.

Le Breton, D. (2013). Une brève histoire de l'adolescence. Paris: JC Béhar.

Lei Federal n.o 8.069, de 13 de julho de 1990. (1990, 27 setembro). Dispõe sobre o Estatuto da Criança e do Adolescente e dá outras providências. Diário Oficial da União, Brasília. 
Lei Federal n. ${ }^{\circ}$ 12.594, de 18 de janeiro de 2012. (2012, 21 janeiro). Institui o Sistema Nacional de Atendimento Socioeducativo (Sinase) e dá outras providências. Brasília: Presidência da República. Recuperado a partir de http:// www.planalto.gov.br/ccivil_03/_ato2011-2014/2012/lei/l12594.htm

Soares, L. E. S (2011). Justiça: pensando alto sobre violência, crime e castigo. Rio de Janeiro: Nova Fronteira.

Souza, J. (2012). Os batalhadores brasileiros: nova classe média ou nova classe trabalhadora? Belo Horizonte: UFMG.

Rousseau, J. J. (2004). Emílio ou Da educação. São Paulo: Martins Fontes.

Telles, V. S. (2010). A cidade nas fronteiras do legal e do ilegal. Belo Horizonte: Argumentum.

Waiselfisz, J. (2012). Mapa da violência no Brasil: 2012. Os novos padrōes da violência homicida no Brasil. São Paulo: Instituto Sangari. Recuperado a partir de http://www.mapadaviolencia.org.br/pdf2012/mapa2012_web.pdf. 